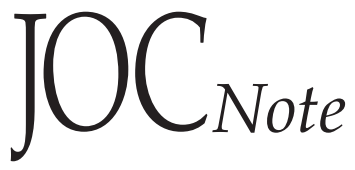

\section{Microwave-Assisted One-Pot Tandem Reactions for Direct Conversion of Primary Alcohols and Aldehydes to Triazines and Tetrazoles in Aqueous Media}

\author{
Jiun-Jie Shie and Jim-Min Fang* \\ Department of Chemistry, National Taiwan University, \\ Taipei 106, Taiwan, and The Genomics Research Center, \\ Academia Sinica, Taipei 115, Taiwan \\ jmfang@ntu.edu.tw
}

Received December 12, 2006

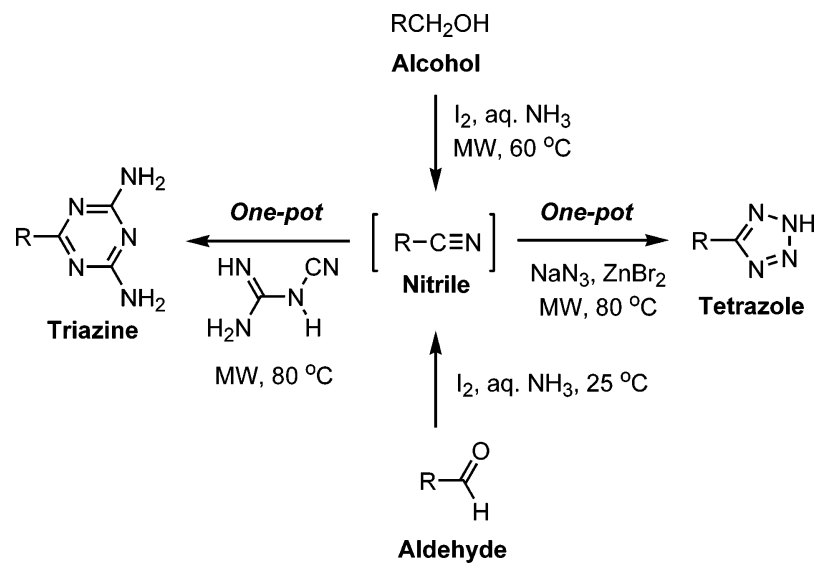

A series of primary alcohols and aldehydes were treated with iodine in ammonia water under microwave irradiation to give the intermediate nitriles, which without isolation underwent $[2+3]$ cycloadditions with dicyandiamide and sodium azide to afford high yields of the corresponding triazines and tetrazoles, including the $\alpha$-amino- and dipeptidyl tetrazoles in high optical purity.

Using water as a safe medium for various organic reactions has been reviewed. ${ }^{1}$ We have previously shown that a variety of aldehydes are converted to their corresponding nitriles using iodine as an appropriate oxidant in ammonia water. ${ }^{2}$ In comparison with similar reactions using liquid ammonia or ammonia gas saturated in alcohol solvents, ${ }^{3}$ operation in ammonia water is simpler and more efficient, giving the nitriles in high yields at room temperature within a short reaction time $(<1 \mathrm{~h})$. Nitrile compounds are viable precursors for preparation of nitrogen-containing functional compounds. ${ }^{4} \mathrm{We}$ have previ-

* To whom correspondence should be addressed. Tel: (886-2)-33661663. Fax: (886-2)-23637812.

(1) (a) Reichardt, C. In Solvents and Solvent Effects in Organic Chemistry; VCH: Weinheim, Germany, 2003. (b) Li, C. J. Chem. Rev. 1993, 93, 2023-2035. (c) Li, C. J. In Organic Reactions in Aqueous Media; Wiley: New York, 1997. (d) Lindström, U. M. Chem. Rev. 2002, 102, 2751-2772. (e) Narayan, S.; Muldoon, J.; Finn, M. G.; Fokin, V. V.; Kolb, H. C.; Sharpless, K. B. Angew. Chem., Int. Ed. 2005, 44, 3275-3279.

(2) Talukdar, S.; Hsu, J.-L.; Chou, T.-K.; Fang, J.-M. Tetrahedron Lett. 2001, 42, 1103-1105. ously demonstrated the tandem reactions of various aldehydes in aqueous media to furnish the corresponding amides, triazines, and tetrazoles via the intermediate nitriles by additions of $\mathrm{H}_{2} \mathrm{O}_{2}$, dicyandiamide/ $\mathrm{KOH}$, and $\mathrm{NaN}_{3} / \mathrm{ZnBr}_{2}$ in one-pot procedures. ${ }^{5}$ Though the reaction of the intermediate nitriles with $\mathrm{H}_{2} \mathrm{O}_{2}$ was carried out smoothly at room temperature, the formation of triazines and tetrazoles still required refluxing (e.g., $\geq 100{ }^{\circ} \mathrm{C}$ ) for a prolonged period $(12-48 \mathrm{~h})$. In order to improve these preparation protocols, we considered using microwave irradiation, which has become a powerful technique to accelerate thermally driven chemical reactions. ${ }^{6}$ It has been shown that aryl halides are converted to the aryl nitriles and further to the aryl tetrazoles in a tandem reaction with sodium azide under microwave irradiation in DMF solution or on solid support. ${ }^{7}$ We anticipated that the similar cycloaddition reactions of nitriles would be enhanced by microwave irradiation, especially in the above-mentioned salt-containing aqueous media that may take microwave energy effectively.

Our study began with the direct conversion of an aldehyde with iodine in ammonia water to a nitrile intermediate, which without isolation was heated with dicyandiamide, using a focused microwave reactor (power of $80-100 \mathrm{~W}$ ), to furnish the $[2+3]$ cycloaddition product 2,6-diamino-1,3,5-triazine in a one-pot operation (Scheme 1 and Table 1). The 1,3-dipolar cycloaddition of nitrile compounds $\mathbf{2 a}-\mathbf{e}$ (generated in situ from aldehydes $1 \mathbf{a}-\mathbf{e}$ ) with dicyandiamide proceeded smoothly at $80{ }^{\circ} \mathrm{C}$ under microwave irradiation. ${ }^{8}$ The reaction time was shortened to $15-30 \mathrm{~min}$, even without using $\mathrm{KOH}$ as an external base, which is often utilized as a promoter in conventional heating methods. ${ }^{5,9}$ Diamino-1,3,5-triazines such as $\mathbf{3 a}-\mathbf{e}$ are a class of compounds possessing diverse bioactivities ${ }^{10}$ and widely used in material design via assembly of the multiple hydrogen-bonded complexes. ${ }^{11}$

(3) Misono, A.; Osa, T.; Koda, S. Bull. Chem. Soc. Jpn. 1967, 40, 28752884

(4) (a) Mowry, D. T. Chem. Rev. 1948, 42, 189-283. (b) Friedrich, K.; Wallensfels, K. In The Chemistry of Cyano Group; Rappoport, Z., Ed.; Wiley-Interscience: New York, 1970. (c) North, M. In Comprehensive Organic Functional Group Transformations; Katritzky, A. R., Meth-Conn, O., Rees, C. W., Eds.; Pergamon: Oxford 1995; pp 617-618.

(5) (a) Shie, J.-J.; Fang, J.-M. J. Org. Chem. 2003, 68, 1158-1160. (b) Taber, D. F. Org. Chem. Highlights: Best Synthetic Methods; March 8, 2004; www.organic-chemistry.org.

(6) (a) Mingos, D. M. P.; Baghurst, D. R. Microwave-Enhanced Chemistry: Fundamentals, Sample Preparation, and Applications; Kingston, H. M., Haswell, S. J., Eds.; American Chemical Society: Washington, DC, 1997. (b) Hayes, B. L. Microwave Syntheses: Chemistry at the Speed of Light; CEM Publishing: Mattews, NC, 2002. (c) De la Hoz, A.; DiazOrtiz, A.; Langa, F. Microwaves Org. Syn. 2002, 295-343. (d) Nuechter, M.; Ondruschka, B.; Bonrath, W.; Gum, A. Green Chem. 2004, 6, 128141. (e) Kuznetsov, D. V.; Raev, V. A.; Kuranov, G. L.; Arapov, O. V.; Kostikov, R. R. Russ. J. Org. Chem. 2005, 41, 1719-1749. (f) Wolkenberg, S. E.; Shipe, W. D.; Lindsley, C. W.; Guare, J. P.; Pawluczyk, J. M. Curr. Opin. Drug Discovery Dev. 2005, 8, 701-708. (g) Westman, J. Microwave Assisted Org. Synth. 2005, 102-132. (h) Leadbeater, N. E. Chem. Commun. 2005, 23, 2881-2902. (i) Kaval, N.; Ermolat'ev, D.; Appukkuttan, P.; Dehaen, W.; Kappe, C. O.; Van der Eycken, E. J. Comb. Chem. 2005, 7, 490-502.

(7) Alterman, M.; Hallberg, A. J. Org. Chem. 2000, 65, 7984-7989.

(8) The cycloadditions of nitriles with dicyandiamide are usually conducted by heating methods; however, an example using microwave irradiation in ionic liquid has been reported. See: Peng, Y.; Song, G. Tetrahedron Lett. 2004, 45, 5313-5316. 
SCHEME 1. Microwave-Assisted One-Pot Tandem Reactions for Direct Conversion of Alcohols and Aldehydes to Triazines and Tetrazoles in Aqueous Media

$$
\mathrm{RCH}_{2} \mathrm{OH}
$$

$8 a, 8 c-e$

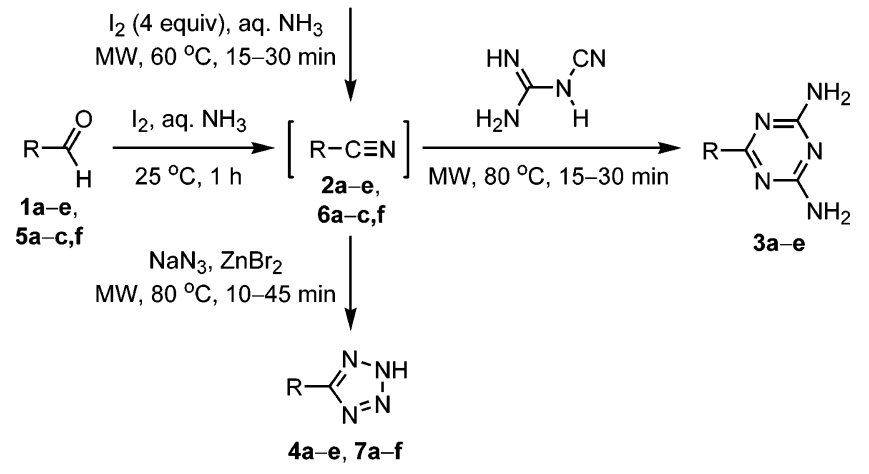

TABLE 1. Direct Conversion of Aldehydes to Triazines and Tetrazoles via Cycloadditions of Intermediate Nitriles with Dicyandiamide and Sodium Azide by Microwave-Assisted Methods

\begin{tabular}{|c|c|c|c|}
\hline \multirow[b]{2}{*}{ aldehyde } & \multirow[b]{2}{*}{$\mathrm{R}=$} & \multicolumn{2}{|c|}{ products (yield, \%) } \\
\hline & & triazine $^{b}$ & tetrazole \\
\hline $1 \mathrm{a}$ & $\mathrm{C}_{6} \mathrm{H}_{5}$ & 3a (71) & $4 \mathbf{a}(79)$ \\
\hline $1 \mathrm{~b}$ & $4-\mathrm{MeOC}_{6} \mathrm{H}_{4}$ & $\mathbf{3 b}(69)$ & 4b (77) \\
\hline 1c & $4-\mathrm{O}_{2} \mathrm{NC}_{6} \mathrm{H}_{4}$ & $3 c(76)$ & $4 c(76)$ \\
\hline 1d & 2 -furyl & 3d (77) & 4d (70) \\
\hline 1e & 2-thienyl & $3 \mathbf{e}(83)$ & $4 \mathbf{e}(83)$ \\
\hline
\end{tabular}

${ }^{a}$ Overall yield of two steps. ${ }^{b}$ The aldehyde was stirred with $\mathrm{I}_{2}$ in ammonia water for $1 \mathrm{~h}$, followed by addition of dicyandiamide, and the mixture was exposed to microwave irradiation at $80{ }^{\circ} \mathrm{C}$ for $15-30$ min ${ }^{c}$ The aldehyde was stirred with $\mathrm{I}_{2}$ in ammonia water for $1 \mathrm{~h}$, followed by addition of $\mathrm{NaN}_{3}$ and $\mathrm{ZnBr}_{2}$, and the mixture was exposed to microwave irradiation at $80^{\circ} \mathrm{C}$ for $10 \mathrm{~min}$.

The microwave-assisted cycloadditions of nitriles with $\mathrm{NaN}_{3}$ and cyanoarylboronate esters with trimethylsilyl azide have been carried out at high temperature $\left(150-220^{\circ} \mathrm{C}\right)$ in DMF or DME solutions. ${ }^{7,12}$ As the drastic reaction conditions and the organic solvents are not preferable, the microwave-assisted reaction in aqueous media is more appealing. ${ }^{1}$ In particular, the high heat capacity of water is able to mitigate the explosion hazards on using sodium azide. In this study, a one-pot procedure for the direct conversion of aldehydes to tetrazoles was carried out by

(9) (a) Smolin, E. M.; Rapoport, I. In The Chemistry of Heterocyclic Compounds; Weissberg, A., Ed.; Wiley: New York, 1959; Vol. 13, s-triazines. (b) Quirke, J. M. E. In Comprehensive Heterocyclic Chemistry; Katritzky, A. R., Rees, C. W., Boulton, A. J., McKillop, A., Eds.; Pergamon: Oxford, 1984; Vol. 3, Chapter 2.20, 1,3,5-Triazines. (c) Cooke, G.; Augier de Cremiers, H.; Rotello, V. M.; Tarbit, B.; Vanderstraeten, P. E. Tetrahedron 2001, 57, 2787-2789.

(10) (a) Hasegawa, Y.; Yanagisawa, T.; Okui, Y.; Sato, T.; Hosaka, K.; Chin, M.; Mitsuhashi, H. Chem. Pharm. Bull. 1991, 39, 3180-3182. (b) Brzozowski, Z.; Saczewski, F.; Gdaniec, M. Eur. J. Med. Chem. 2000, 35, 1053-1064. (c) Jensen, N. P.; Ager, A. L.; Bliss, R. A.; Canfield, C. J.; Kotecka, B. M.; Rieckmann, K. H.; Terpinski, J.; Jacobus, D. P. J. Med. Chem. 2001, 44, 3925-3931. (d) Baindur, N.; Chadha, N.; Brandt, B. M.; Asgari, D.; Patch, R. J.; Schalk-HiHi, C.; Carver, T. E.; Petrounia, I. P.; Baumann, C. A.; Ott, H.; Manthey, C.; Springer, B. A.; Player, M. R. J. Med. Chem. 2005, 48, 1717-1720. (e) Saczewski, F.; Bulakowska, A.; Bednarski, P.; Grunert, R. Eur. J. Med. Chem. 2006, 41, 219-225.

(11) (a) Beijer, F. H.; Sijbesma, R. P.; Vekemans, J. A. J. M.; Meijer, E. W.; Kooijman, H.; Spek, A. L. J. Org. Chem. 1996, 61, 6371-6380. (b) Deans, R.; Rotello, V. M. J. Org. Chem. 1997, 62, 4528-4529. (c) Balogh, D. T.; Dhanabalan, A.; Dynarowicz-Latka, P.; Schenning, A. P. H. J.; Oliveira, O. N., Jr.; Meijer, E. W.; Janssen, R. A. J. Langmuir 2001, 17, 3281-3285. (d) Frankamp, B. L.; Uzun, O.; Ilhan, F.; Boal, A. K.; Rotello, V. M. J. Am. Chem. Soc. 2002, 124, 892-893. the microwave-assisted method. Thus, aldehydes $\mathbf{1 a}-\mathbf{e}$ were subjected to oxidation with $\mathrm{I}_{2}$ in ammonia water and in situ cycloadditions with $\mathrm{NaN}_{3} / \mathrm{ZnBr}_{2}$ by microwave irradiation at $80{ }^{\circ} \mathrm{C}$ for $10 \mathrm{~min}$ to give the 5-aryl-1,2,3,4-tetrazoles $\mathbf{4 a}-\mathbf{e}$ in $70-83 \%$ overall yields (Table 1). In comparison with the conventional heating method using prolonged reflux (17-48 h) at a high temperature $\left(>100{ }^{\circ} \mathrm{C}\right),{ }^{5,13}$ the current microwaveaccelerated reaction in aqueous media is safer and more efficient.
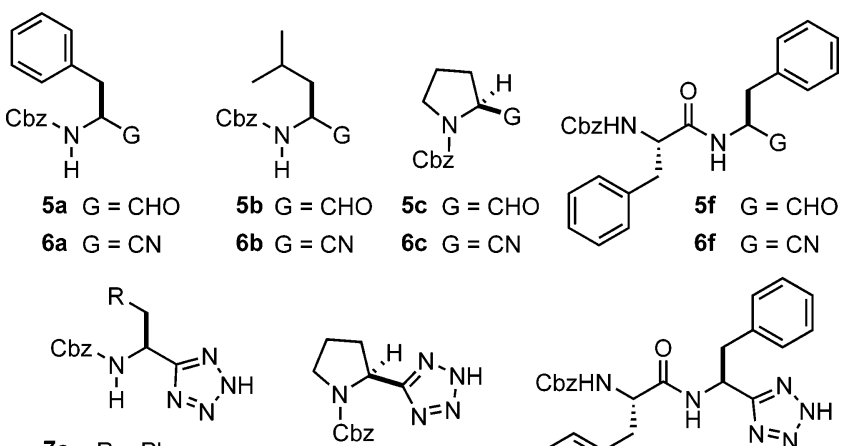

7a $\quad \mathrm{R}=\mathrm{Ph}$

7b $\mathrm{R}=\mathrm{Me}_{2} \mathrm{CH}$

$7 c$<smiles>O=C(NC(=O)[C@H](Cc1ccccc1)NC(=O)c1nn[nH]n1)OCc1ccccc1</smiles>

7d $\mathrm{R}=4-\mathrm{Bu}^{t} \mathrm{OC}_{6} \mathrm{H}_{4}$

7e $\quad \mathrm{R}=$ Indol-3-yl

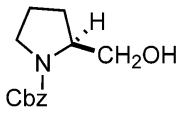

$8 \mathrm{c}$
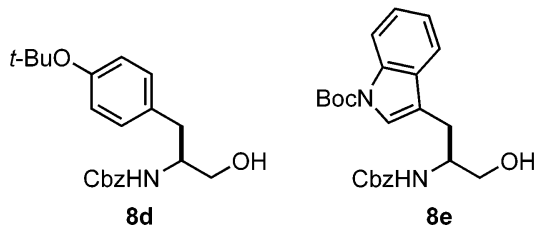

We also prepared the $N$-Cbz- $\alpha$-aminonitriles $6 \mathbf{6}-\mathbf{c}$ and dipeptidyl nitrile $\mathbf{6} \mathbf{f}$ by a similar approach, ${ }^{5}$ i.e., treatment of appropriate aldehydes $\mathbf{5 a}-\mathbf{c}$ with $\mathrm{I}_{2}$ in ammonia water at room temperature. ${ }^{16}$ Furthermore, the $N$-Cbz- $\alpha$-aminonitriles $6 \mathbf{a}-\mathbf{c}$ generated in situ were treated with $\mathrm{NaN}_{3}$ and $\mathrm{ZnBr}_{2}$ under microwave irradiation for $30 \mathrm{~min}$ to furnish the $N$-Cbz- $\alpha$ aminotetrazoles $\mathbf{7 a}-\mathbf{c}$ in high yields $(84-88 \%) .{ }^{14}$ The microwaveassisted direct conversion of dipeptidyl aldehyde $\mathbf{5} \mathbf{f}$ to dipeptidyl tetrazole $7 \mathbf{f}$ ( $78 \%$ yield) was similarly carried out. The ${ }^{1} \mathrm{H}$ NMR analysis $(600 \mathrm{MHz})$ indicated that no apparent existence of the diastereomers of $\mathbf{7 f}$ (see Supporting Information).

The scope of this method was further broadened by combination with the direct oxidative conversion of primary alcohols to nitriles in iodine-ammonia water. ${ }^{15}$ Thus, the microwavepromoted reactions of benzyl alcohol $(\mathbf{8 a}), N$-Cbz-prolinol $(\mathbf{8 c})$, and the tyrosine-derived primary alcohol $(\mathbf{8 d})$ with iodine $(4$ equiv) in ammonia water gave the corresponding nitriles, which underwent cycloadditions with sodium azide in one pot to

(12) (a) Koldobskii, G. I. Russ. J. Org. Chem. 2006, 42, 469-486. (b) Duncia, J. V.; Pierce, M. E.; Santella, J. B., III. J. Org. Chem. 1991, 56, 2395-2400. (c) Huff, B. E.; Staszak, M. A. Tetrahedron Lett. 1993, 34, 8011-8014. (d) Koguro, K.; Oga, T.; Mitsui, S.; Orita, R. Synthesis 1998, 910-914. (e) Curran, D. P.; Hadida, S.; Kim, S.-Y. Tetrahedron 1999, 55, 8997-9006. (f) Schulz, M. J.; Coats, S. J.; Hlasta, D. J. Org. Lett. 2004, 6, 3265-3268.

(13) (a) Demko, Z. P.; Sharpless, K. B. Org. Lett. 2001, 3, 4091-4094. (b) Demko, Z. P.; Sharpless, K. B. J. Org. Chem. 2001, 66, 7945-7950. (c) Demko, Z. P.; Sharpless, K. B. Angew. Chem., Int. Ed. 2002, 41, 21102113. (d) Demko, Z. P.; Sharpless, K. B. Angew. Chem., Int. Ed. 2002, 41, 2113-2116. (e) Himo, F.; Demko, Z. P.; Noodleman, L.; Sharpless, K. B. J. Am. Chem. Soc. 2002, 124, 12210-12216. (f) Himo, F.; Demko, Z. P.; Noodleman, L.; Sharpless, K. B. J. Am. Chem. Soc. 2003, 125, 99839987.

(14) Demko, Z. P.; Sharpless, K. B. Org. Lett. 2002, 4, 2525-2527.

(15) Mori, N.; Togo, H. Synlett 2005, 1456-1458. 
furnish the desired tetrazole products $\mathbf{4 a}, \mathbf{7 c}$, and $\mathbf{7 d}$ in $80 \%$, $77 \%$, and $82 \%$ yields, respectively. The direct conversion of the tryptophan-derived primary alcohol $\mathbf{8 e}$ was similarly performed, albeit by using a larger quantity of $\mathrm{NaN}_{3}$ (18 equiv) and $\mathrm{ZnBr}_{2}$ (9 equiv) for a longer period (45 min), to obtain a $70 \%$ yield of the tryptophan tetrazole $7 \mathbf{e}$ with concomitant removal of the Boc group. The cycloaddition of the tryptophan nitrile generated from 8e was more sluggish presumably as a result of its low solubility in the reaction conditions. The $\alpha$-aminotetrazoles $\mathbf{7 a}-\mathbf{e}$ prepared as such showed only minimal racemerization $(3.5-6 \%)$ during the microwave-assisted onepot tandem reactions according to the HPLC analyses on a chiral column (see Supporting Information).

We have demonstrated an expedient microwave-assisted method for the direct transformation of primary alcohols and aldehydes into triazines and tetrazoles in aqueous media. The alcohols and aldehydes reacted with iodine in ammonia water to provide the corresponding nitrile intermediates (e.g., $\mathbf{2} \mathbf{a}-\mathbf{e}$, $\mathbf{6 a}-\mathbf{c}$, and $\mathbf{6 f}$ ), which readily underwent $[2+3]$ cycloadditions with dicyandiamide and sodium azide on exposure to microwave irradiation to give the corresponding 4-aryl-2,6-diamino-1,3,5triazines $(\mathbf{3 a}-\mathbf{e}), 5$-aryl-1,2,3,4-tetrazoles $(\mathbf{4 a}-\mathbf{e}), N$-Cbz- $\alpha$ aminotetrazoles $(\mathbf{7 a}-\mathbf{c})$, and dipeptidyl tetrazole $(\mathbf{7 f})$ in a onepot operation. This method circumvents the problem in prior preparation of nitrile compounds from halides and toxic cyanides. The one-pot tandem reactions were conducted in aqueous media, and the products (triazines and tetrazoles) were obtained simply by extraction or filtration. In comparison with the previously reported heating methods, microwave irradiation has an advantage in the acceleration of reactions. No caustic $\mathrm{KOH}$ was required in the microwave-accelerated synthesis of triazines.

The optically active $\alpha$-aminotetrazoles, e.g., 7c derivative of L-proline, have been employed as versatile chiral catalysts in organic reactions. ${ }^{16}$ Because the tetrazole products have a striking structural resemblance to their triazole analogues, our method for an easy access to optically active $\alpha$-aminotetrazoles in aqueous media may have a growing impact on drug discovery similar to that demonstrated by the click chemistry of alkynes with azides. ${ }^{17}$

\section{Experimental Section}

CAUTION: Iodine may react with ammonia water under certain conditions to give the explosive powder nitrogen triiodide monoamine $\left(\mathrm{NI}_{3} \cdot \mathrm{NH}_{3}\right),{ }^{18}$ and the reaction of sodium azide may release a minute amount of hazardous hydrazoic acid $\left(\mathrm{HN}_{3}\right)$. Although we

(16) Hartikka, A.; Arvidsson, P. I. Tetrahedron: Asymmetry 2004, 15 , $1831-1834$.

(17) (a) Kolb, H. C.; Sharpless, K. B. Drug Discovery Today 2003, 8 , 1128-1137. (b) Kolb, H. C.; Finn, M. G.; Sharpless, K. B. Angew. Chem., Int. Ed. 2001, 40, 2004-2021. (c) Prescher, J. A.; Bertozzi, C. R. Nat. Chem. Biol. 2005, 1, 13-21. (d) Van Swieten, P. F.; Leeuwenburgh, M. A.; Kessler, B. M.; Overkleeft, H. S. Org. Biomol. Chem. 2005, 3, 2027. (e) Lewis, W. G.; Green, L. G.; Grynszpan, F.; Radic, Z.; Carlier, P. R.; Taylor, P.; Finn, M. G.; Sharpless, K. B. Angew. Chem., Int. Ed. 2002, 41, 1053-1057. (f) Lee, L. V.; Mitchell, M. L.; Huang, S.-J.; Fokin, V. V.; Sharpless, K. B.; Wong, C.-H. J. Am. Chem. Soc. 2003, 125, $9588-$ 9589. (g) Krasinski, A.; Radic, Z.; Manetsch, R.; Raushel, J.; Taylor, P.; Sharpless, K. B.; Kolb, H. C. J. Am. Chem. Soc. 2005, 127, 6686-6692. (h) Whiting, M.; Muldoon, J.; Lin, Y.-C.; Silverman, S. M.; Lindstrom, W.; Olson, A. J.; Kolb, H. C.; Finn, M. G.; Sharpless, K. B.; Elder, J. H.; Fokin, V. V. Angew. Chem., Int. Ed. 2006, 45, 1435-1439.

(18) (a) Southwick, P. L.; Christman, D. R. J. Am. Chem. Soc. 1952 74, 1886-1891. (b) Roesky, H. W.; Möckel, K. In Chemical Curiosities; VCH: Weinheim, Germany 1996; pp 292-293. did not encounter any incidents in this study, one should avoid using excess reagents or high concentrations of iodine-ammonia water and sodium azide in the following procedures.

General Procedure for Direct Conversion of Aldehydes to Triazines Using Microwave Irradiation. A solution of aromatic aldehyde $(\mathbf{1 a}-\mathbf{e}, 1 \mathrm{mmol})$ and iodine $(1.1 \mathrm{mmol})$ in ammonia water $(9 \mathrm{~mL}$ of $28 \%$ solution) and THF $(1 \mathrm{~mL})$ was placed in a roundbottomed flask equipped with a condenser. The dark solution was stirred for $1 \mathrm{~h}$ at room temperature and became colorless at the end of the reaction. After addition of dicyandiamide $(1.1 \mathrm{mmol})$, the mixture was irradiated in a single mode microwave reactor $(100$ $\mathrm{W}$ power) at approximately $80^{\circ} \mathrm{C}$ (as indication of the reactor's temperature setting) for $15-30 \mathrm{~min}$. The reaction mixture was cooled; the precipitates were filtered and rinsed with $\mathrm{Et}_{2} \mathrm{O}$ to give the desired pure product 6-aryl-2,4-diamino-1,3,5-triazine $(3 \mathbf{a}-\mathbf{e})$ in $69-83 \%$ yields (Table 1). The physical and spectroscopic properties of $\mathbf{3 a}-\mathbf{e}$ were in agreement with those data previously reported (see Supporting Information).

General Procedure for Direct Conversion of Aldehydes to Tetrazoles Using Microwave Irradiation. A solution of $\alpha$-aminoaldehyde $(\mathbf{5 a}, 1 \mathrm{mmol})$ and iodine $(1.1 \mathrm{mmol})$ in ammonia water ( $8 \mathrm{~mL}$ of $28 \%$ solution) and THF $(2 \mathrm{~mL})$ was stirred at room temperature for $1-2 \mathrm{~h}$. The dark solution became colorless at the end of reaction. $\mathrm{NaN}_{3}(4 \mathrm{mmol})$ and $\mathrm{ZnBr}_{2}(2 \mathrm{mmol})$ were then added sequentially. The reaction mixture was exposed to microwave irradiation $(80 \mathrm{~W})$ at $80^{\circ} \mathrm{C}$ for $30 \mathrm{~min}$. The reaction mixture was cooled, aqueous $\mathrm{HCl}$ (1 M solution) and EtOAc were added, and the mixture was vigorously stirred until no solid was present. The organic layer was separated, and the aqueous layer was extracted with EtOAc $(2 \times)$. The combined organic layers were dried over $\mathrm{MgSO}_{4}$, filtered, and concentrated under reduced pressure. The desired $(S)$ - $N$-Cbz- $\alpha$-aminotetrazole $7 \mathbf{a}$ was obtained in $88 \%$ yield by crystallization from $\mathrm{EtOAc} / \mathrm{Et}_{2} \mathrm{O}$ solution.

Conversion of aldehydes $\mathbf{1 a}-\mathbf{e}, \mathbf{5 b}, \mathbf{5} \mathbf{c}$, and $\mathbf{5 f}$ to the corresponding tetrazoles $\mathbf{4 a}-\mathbf{e}, \mathbf{7 b}, \mathbf{7 c}$, and $\mathbf{7 f}$ using microwave irradiation was carried out by the procedure described for $\mathbf{7 a}$. The physical and spectroscopic properties of tetrazoles $4 \mathbf{a}-\mathbf{e}$ and $7 \mathbf{a}-\mathbf{c}$ were in agreement with the previously reported data. ${ }^{5,14}$

General Procedure for Direct Conversion of $\alpha$-Amino Alcohols to $\alpha$-Aminotetrazoles Using Microwave Irradiation. A solution of (S)-(benzyloxycarbonyl)prolinol $\mathbf{8 c}(3 \mathrm{mmol})$ and iodine (12 mmol) in ammonia water (12 mL of $28 \%$ solution) and THF $(3 \mathrm{~mL})$ was placed in a round-bottomed flask equipped with a condenser. The mixture was stirred for $5 \mathrm{~min}$ at room temperature and exposed to microwave irradiation in a single mode microwave reactor $\left(100 \mathrm{~W}\right.$ ) at $60{ }^{\circ} \mathrm{C}$ (as indication of the reactor's temperature setting) for $15-30 \mathrm{~min}$. The mixture was cooled to room temperature, $\mathrm{NaN}_{3}(12 \mathrm{mmol})$ and $\mathrm{ZnBr}_{2}(6 \mathrm{mmol})$ were added sequentially, and the mixture was again subjected to microwave irradiation at $80{ }^{\circ} \mathrm{C}$ for $30 \mathrm{~min}$. The reaction mixture was cooled, aqueous $\mathrm{HCl}$ ( $1 \mathrm{M}$ solution) and EtOAc were added, and the mixture was vigorously stirred until no solid was present. The organic layer was separated, and the aqueous layer was extracted with EtOAc $(2 \times)$. The combined organic layers were dried over $\mathrm{MgSO}_{4}$, filtered, concentrated, and chromatographed on a silica gel column to give the desired $(S)$-tetrazole product $7 \mathrm{c}$ ( $77 \%$ yield, $93 \%$ ee).

Conversion of benzyl alcohol (8a) and the tyrosine- and tryptophan-derived primary alcohols $\mathbf{8 d}$ and $\mathbf{8 e}$ using microwave irradiation was carried out by the procedure described for $\mathbf{8 c}$, giving the tetrazoles $\mathbf{4 a}$ ( $80 \%$ yield), $7 \mathbf{d}$ (82\% yield, $92 \%$ ee), and $7 \mathbf{e}$ (70\% yield, $88 \%$ ee), respectively. The physical and spectroscopic properties of $\mathbf{7} \mathbf{c}$ and $7 \mathbf{e}$ are listed in Supporting Information.

HPLC Analysis. The enantiomeric purity of tetrazoles $7 \mathbf{a}-\mathbf{e}$ was determined by HPLC analysis on a Chiralcel OD-H column $(0.46$ $\mathrm{cm}$ i.d. $\times 25 \mathrm{~cm})$ at $30^{\circ} \mathrm{C}$. The tetrazole sample $(5.0 \mathrm{mg} / \mathrm{mL}$ in 2-propanol) was prepared, and $20 \mu \mathrm{L}$ was loaded for each analysis. The mobile phase of hexane/2-propanol $(85: 15$, v/v) with a flow rate of $0.5 \mathrm{~mL} / \mathrm{min}$ was applied, and the signals of the sample were 


\section{JOCNote}

recorded by a UV detector at $206 \mathrm{~nm}$ wavelength. The ratio of enantiomers was calculated from the areas of each enantiomer signals.

Acknowledgment. We thank the National Science Council for financial support.
Supporting Information Available: General experimental section, characterization of compounds, ${ }^{1} \mathrm{H}$ and ${ }^{13} \mathrm{C}$ NMR spectra of new compounds, and HPLC analyses of tetrazoles $\mathbf{7 a}-\mathbf{e}$. This material is available free of charge via the Internet at http://pubs.acs.org.

JO0625352 